\title{
Marking by elytral clip changes stridulatory characteristics and reduces reproduction in the American burying beetle, Nicrophorus americanus
}

\author{
Carrie L. Hall • Daniel R. Howard • \\ Rosemary J. Smith · Andrew C. Mason
}

Received: 5 August 2014/ Accepted: 6 January 2015/Published online: 22 January 2015

(C) The Author(s) 2015. This article is published with open access at Springerlink.com

\begin{abstract}
Some insects produce and use sound during multiple behaviors including many aspects of reproduction. Variation in call structure depends on the evolved morphological structures used to produce the sound and encode function. Beetles in the genus Nicrophorus produce stridulation by rubbing plectra, located on the ventral side of the elytra, against a pars stridens, located on the caudal end on the fourth and fifth abdominal segment in females and males, respectively. During field surveys for the endangered $N$. americanus, survey crews have historically used a small V-shaped notch cut in the caudal end of the right elytron to serves as a permanent marking method. No study, however, has examined the effect of this marking technique on the characters of stridulation or consequences
\end{abstract}

Electronic supplementary material The online version of this article (doi:10.1007/s10841-015-9755-8) contains supplementary material, which is available to authorized users.

\section{L. Hall $(\varangle)$. D. R. Howard}

Department of Biology, Augustana College, 2001 S. Summit

Avenue, Sioux Falls, SD 57197, USA

e-mail: carrie.hall@augie.edu

D. R. Howard

e-mail: daniel.howard@augie.edu

\section{L. Hall · R. J. Smith}

Department of Biological Sciences, Idaho State University, 921 South 8th Ave., Stop 8007, Pocatello, ID 83209, USA e-mail: smitrose@isu.edu

\section{A. C. Mason}

Department of Biological Sciences, University of Toronto at Scarborough, 1265 Military Trail, Scarborough, ON M1C 1A4, Canada

e-mail: amason@utsc.utoronto.ca for reproductive behavior and fitness. Here we show that one temporal and one spectral character of sound change significantly following elytron clipping, and that reproductive success is significantly decreased in all breedings in which a parent beetle is elytron-clipped. We recommend replacement of this marking technique with non-invasive methods to ensure conservation of this endangered species.

Keywords Nicrophorus americanus · Elytron clipping · Stridulation $\cdot$ Marking technique $\cdot$ Biacoustics

\section{Introduction}

Some insects produce and use sound during multiple behaviors including predator avoidance, prey location, sexual advertisement, and mate choice and localization (Alexander 1962; Forrest and Green 1991; Montealegre-Z and Mason 2005; Morris and Beier 1982). In particular for orthopterans and coleopterans, sounds are produced by rubbing together specialized structures on the wings or elytra, femurs, and/or other body structures that are then amplified and broadcast (Alexander 1967; Alexander et al. 1963; Arrow 1942; Bradbury and Vehrencamp 1998). Structures used to produce stridulatory sound include raised, sclerotized plectra and a rigid file of individual teeth that together form the stridens. The particular characteristics of the sounds these structures produce usually depends on the morphology of the structures and the musculature employed to facilitate contact between them, the physiological constraints of body size, and the calling effort of the insect (Bennet-Clark 1975, 1998; Montealegre-Z and Mason 2005). Further, the spectral content of the sounds, whether in the form of a pure tone, harmonic, or broadband sound, is a direct result of this structural morphology (Claridge 1974; 
Hyder and Oseto 1989), while the temporal components of the sound are determined by the effort and energy the animal uses to produce the sound (Bennet-Clark 1975, 1989, 1999; Howard and Hill 2006; Montealegre-Z and Mason 2005; Prestwich 1994; Ryan 1988). Structures involved in sound production contribute to the characteristics of the sound (Arrow 1942), and so the removal of, or alteration of any part of the acoustic anatomy can change these characteristics (see Alexander 1967; Alexander et al. 1963; Arrow 1942).

Variation in call structure depend on the evolved morphological structures used to produce the sound and their function (Alexander 1962; Bradbury and Vehrencamp 1998). Sexual selection has resulted in the evolution of structures that produce sounds unique to each calling insect to increase the fitness of the caller. Other sounds such as alarm calls or aggregation signals are not sexually selected, but have evolved under natural selection gradients and generally exhibit more broadband frequencies so that receivers, regardless of frequency tuning, can hear the alarm sounds and respond. The structures used to produce these sounds may be very similar to those used to produce sexual signals, but the function and context of the sound differs (Alexander et al. 1963).

The few bioacoustics studies of coleopterans have focused primarily on defensive stridulations (Buchler et al. 1981; Deroe and Pasteels 1977), and applied methodological research designed to exploit the stridulations of species designated as pests (Kasper and Hirschberger 2005; Mankin et al. 2009). However, little is known about the role sound plays in the life history of most beetle species, and no studies to date have investigated the role of sound quality in the context of life history, behavior, or soundproducing structures. Knowledge of sound quality (pure tone, harmonic, or broadband) and signal structure (temporal measures of sound), as well as an understanding of the stridulatory structure morphology, could lead to further understanding of function of the sound and ultimately its evolutionary trajectory.

Burying beetles in the genus Nicrophorus use stridulation during behaviors associated with reproduction such as during contests for carrion resources, copulation, and care of offspring (Huerta et al. 1992; Milne and Milne 1944; Pukowski 1933; Schumacher 1973). The stridulations are produced by rubbing plectra (located on the ventral side of the elytra) against a pars stridens (located, from the caudal end, on the fifth abdominal segment of the male, and the fourth segment of the female) (Hall et al. 2013; Pukowski 1933; Schumacher 1973). Pukowski (1933) and Milne and Milne (1944) observed this behavior during competition for carcasses and copulation, and when an obstruction blocks efforts to move a carcass to a suitable burial location. Milne and Milne (1944) reported the unique observation that a Nicrophorus tomentosus beetle with a broken elytron seemed unable to "focus" on the burial process and left its mate alone at the carcass while flying away and returning repeatedly.

Over the past century, populations of Nicrophorus americanus Olivier (the American burying beetle, or "ABB") have declined from a geographic extent that once included 36 States and two Provinces in eastern Canada. As of 2013, the range of the American burying beetle had been reduced to just eight states. The beetle was granted endangered status in 1989, and the US Fish and Wildlife Service (USF\&WS) began efforts to protect existing populations, locate previously undocumented populations, and reintroduce insects into areas of the historic home range. Extensive research into aspects of the American burying beetles ecology, including habitat preferences, nutritional requirements, reproductive behaviors, and life history, are helping researchers understand the breadth of the species' ecological niche (Anderson 1982; Bedick et al. 1999; Creighton et al. 1993, 2009; Sikes and Raithel 2002). No work, however, has thus far focused on intraspecific acoustic communication in this species.

Hall et al. (2013) was the first to characterize the sound and the anatomical structure of the pars stridens of eight North American species of Nicrophorus, and this work suggests that the spectra of the sounds produced by $\mathrm{Ni}$ crophorus are broadband and species-specific, and that temporal measures correlate in a species-by-species manner. Stridulations of the endangered American burying beetle ( $N$. americanus) have a spectral dominant frequency of $\sim 5 \mathrm{kHz}$, but with broadband signature ranging from $\sim 5$ to $10 \mathrm{kHz}$. Temporally, pulses have a duration of $\sim 0.188 \mathrm{~s}$, contain $\sim 87$ syllables pulse ${ }^{-1}$, and have an average interpulse interval of around $0.034 \mathrm{~s}$ (Hall et al. 2013). Observations of this stridulatory behavior using high-speed videography (Hall pers. obs.) show some lateral movement of the abdomen during stridulation, which reduces contact between the pars stridens and the plectra, often involving a single stridens rather than both. It is not known, however, if and to what extent stridulation acts as an intraspecific communication signal during reproduction, whether the elytra are involved in sound quality characteristics, and whether structural damage to the elytron and plectrum alters the characteristics of the call.

During population monitoring surveys for the endangered $N$. americanus, survey crews use both bee tags and elytron clipping to individually mark and identify $N$. americanus captures during annual multi-night MarkRelease-Recapture surveys. In elytra clipping, a small $\mathrm{V}$-shaped notch is cut in the caudal end of the right elytron using small scissors or a heated cautery tool, and serves as a permanent marking method in case bee tags are dislodged from the insect (Fig. 1). Additionally, in field conditions workers may unintentionally remove part of the plectrum while applying the elytron clip (Perotti, 


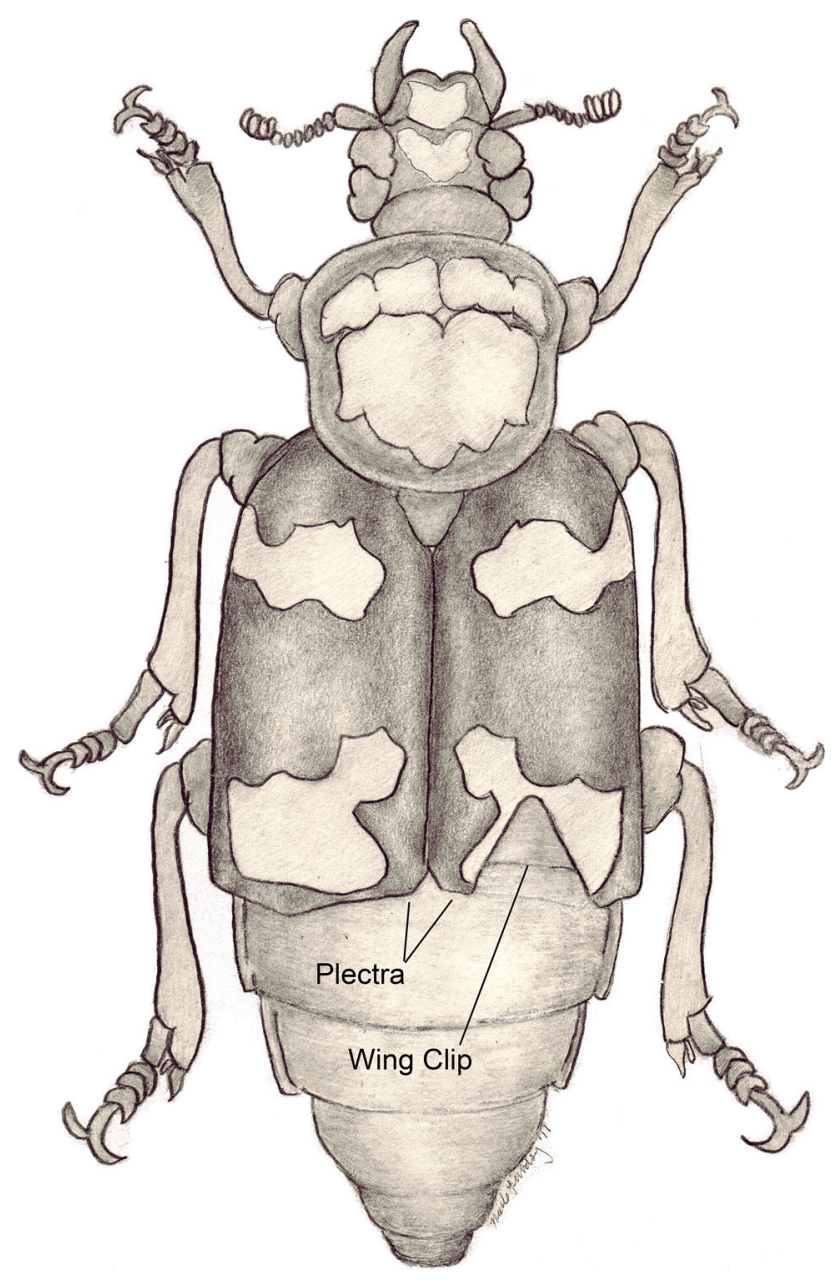

Fig. 1 Diagram showing the location and relative size of the wing clip used as a marking technique during presence/absence surveys for the endangered American burying beetle, $N$. americanus. The $2-3 \mathrm{~mm}$ wing clip is placed in the caudal margin of the right elytron, lateral to or including the area of the plectral on the ventral surface of the right elytron (original artwork by Nicole Lindsey)

pers. comm; pers. obs.). The elytron clip typically measures $2-3 \mathrm{~mm}$ in size (Fig. 1). This practice, though approved under the authority of the US Fish and Wildlife Service, is known to cause loss of hemolymph and permanently alter the elytron structure of the beetle (Perroti, unpublished data; pers. obs.). In many cases, marking techniques used for ecological studies of animal behavior are used with the untested assumptions that marking does not affect the animal, or that negative effects do not result in changes in behavior (in Murray and Fuller 2000). In recent years, however, a growing body of literature is revealing unintended deleterious consequences of marking techniques (Burley 1985; Hagler and Jackson 2001; Murray and Fuller 2000; Zann and Runciman 1994), further emphasizing the need for testing of marking techniques prior to field deployment (Murray and Fuller 2000).
Here we examine the relation of elytra structure and stridulatory sound characteristics, and the role that elytron clipping plays in altering sound characteristics and affecting reproduction in the endangered America burying beetle, $N$. americanus. To assess the influence of elytron clipping on sound and reproduction in N. americanus, we asked the following questions:

1. Does elytron clipping alter the sound characteristics of $N$. americanus stridulation?

2. If so, does the resulting alteration in sound affect reproductive success of $N$. americanus?

Because elytron and/or wing structure often determines sound properties in acoustically communicating insects (Bennet-Clark 1970, 1975; Montealegre-Z and Mason 2005), we tested the hypothesis that elytron clipping alters sound properties of $N$. americanus stridulation, and in particular the spectral characters (dominant frequency and energy peaks) of the sound. This prediction stems from research indicating that elytron structure frequently acts as a resonant structure that not only amplifies sound, but also contributes to the vibratory tone (i.e. frequency) of the sound. We also hypothesized that the reproductive success of paired N. americanus is reduced if sound characteristics of the stridulation were altered as a result of the elytron clip. Additionally, Pukowski (1933) noted that newly hatched first instar larvae arrive at the carcass following stridulation from the female parent, though no subsequent study has explicitly addressed this observation. We predicted, therefore, that if reproductive success is reduced in experimental treatments with elytron clipped adults, that the treatments in which the female parent was elytron clipped should show a greater reduction in total number of offspring than in those treatments in which only the male parent was elytron clipped.

\section{Methods}

Sound recordings and analysis

In 2010, stridulation recordings were collected from five randomly selected virgin male and virgin female $N$. americanus beetles from the captive bred population of the St. Louis Zoo Center for American Burying Beetle Conservation. Recordings were collected prior to and following elytron clipping from each individual using a TASCAM HD-P2 Portable High-Definition Stereo Audio Recorder (TEAC America, Inc. Montebello, CA) equipped with a G.R.A.S. $1 / 4^{\prime \prime}$ condenser microphone (Type 40BE) and Type $26 \mathrm{CB}$ preamplifier powered by a Type $12 \mathrm{AL}$ CCP power supply module (G.R.A.S. Sound and Vibration A/S, Denmark). The recording preparation was secured using a 
Gorillapod flexible tripod (Joby Inc., San Francisco, CA). Beetles were positioned directly in front of the microphone beyond the near-field distance for their respective wavelengths, and three $30 \mathrm{~s}$ sound files were recorded from each beetle. Stridulation was induced by handling. All sound files were recorded at a constant room temperature of $21{ }^{\circ} \mathrm{C}$. For elytron clipped sound recordings, a 2-3 mm Vshaped notch was cut in the caudal margin of the right elytron (Fig. 1). This method replicates the marking method used during Oklahoma field surveys, where the notch measures $2-3 \mathrm{~mm}$ across the caudal edge of the elytron (e.g. the hypotenuse of the V notch).

Digital sound recordings (.wav format) of pre and post elytron-clipping were analyzed in $5 \mathrm{~s}$ durations using SoundRuler sound analysis software (SourceForge version 0.9.6.0, University of California Los Angeles, USA) for pulses/s, pulse duration, and interpulse interval. Duty cycle was calculated from these values [(pulse duration/pulse period) $\times 100$ ]. To analyze syllables/pulse, a bitmap file of the SoundRuler display was captured using ImageJ (version $1.43 \mathrm{~h}$; National Institutes of Health, USA), and syllables were counted using the Cell Counter extension. Dominant frequency and spectral ranges were analyzed using a proprietary script (Unisig) in MATLAB (The MathWorks, Inc. version 7.5.0.342(R2007b), USA), using a 512 pt. resolution Welch window.

\section{Breeding experiments}

The five elytron clipped males and females used for sound recordings were used for experimental breedings along with additional individuals paired as follows, and in accordance with the established breeding protocol for the species (Kozol et al. 1998). A male and female beetle were placed in a soil-filled 19 litre bucket with a quail carcass $(130 \pm 1.0 \mathrm{~g})$ (RodentPro.com, Evansville, IN, USA) in the following experimental treatments:

1. Female with clipped right elytron $(\mathrm{N}=10)$

2. Male with clipped right elytron $(\mathrm{N}=10)$

3. Female and male with clipped right elytron $(\mathrm{N}=15)$

4. Neither female nor male clipped (control) $(\mathrm{N}=15)$

Containers were maintained indoors $(22 \mathrm{C})$ at the Center for American Burying Beetle Conservation at the St. Louis Zoo (St. Louis, Missouri, USA), on a 14:10 h light:dark cycle to mimic summer breeding season day length. Buckets were covered with a screened lid to contain insects and allow for ventilation. Water was added to the containers every other day to maintain soil moisture. All containers were checked daily for reproductive stage and behaviors (copulation, carcass preparation, presence of larvae, eclosure or brood abandonment by the adult(s), larval wandering prior to pupation). The number of offspring to eclose as adults was recorded as a measure of reproductive success for the parents.

Statistical analysis

To test for the influence of elytron clipping on sound characteristics, the twelve sound variables were compared by treatment condition (pre-clip vs. post-clip). We used Multiple Factor Analysis (MFA) to collapse pre- and post-clipped acoustic data into two unique sets of factors with eigenvalues $>1$, and then examined the loading structure of the factors with respect to variable treatment condition (pre- vs. post clipping). We then selected candidate acoustic variables for repeated measures paired analyses based upon their pre-clip versus post-clip quadrant displacement in the final MFA plot, which provided an indication of axes shifts in the characters. These candidate variables were tested for paired differences using a Related Samples Wilcoxon Sign Rank test, with family-wise error rate controlled through Bonferroni correction.

The number of offspring per treatment was examined for normality using a Shapiro-Wilk Goodness-of-fit test, and a Kruskal-Wallis Rank Sums test was then used to examine differences between control and treatment classes. We followed with post hoc pairwise multiple comparison tests to examine differences between predictor variable classes using the Dunn-Bonferroni method. To maintain the family-wise error rate we calculated an adjusted $P$ value for all pairwise comparisons as $P_{\text {adj }}=P \mathrm{~K}(\mathrm{~K}-1) / 2$. All tests were two-tailed with an alpha criteria of 0.05 , and were conducted in SPSS version 21 statistical software (IBM Corporation, Armonk, NY).

\section{Results}

Sound recordings and analysis

Twelve sound characters (Fig. 2) were derived from audio recordings taken from ten $N$. americanus adults (Table 1). Hall et al. (2013) found no difference in sound between females and males; we confirmed this lack of dimorphism in our dataset, and then combined the data for all further analyses. Examination of the acoustic properties of the beetle stridulations prior to and after elytron clipping identified a significant change in one temporal characteristic, interpulse interval of the minor pulse $(\mathrm{t}=-2.830$, $d f=9, P=0.020)$, and a marginally insignificant change in the energy peak of the major pulse $(\mathrm{t}=2.179, d f=9$, $P=0.057)$. 


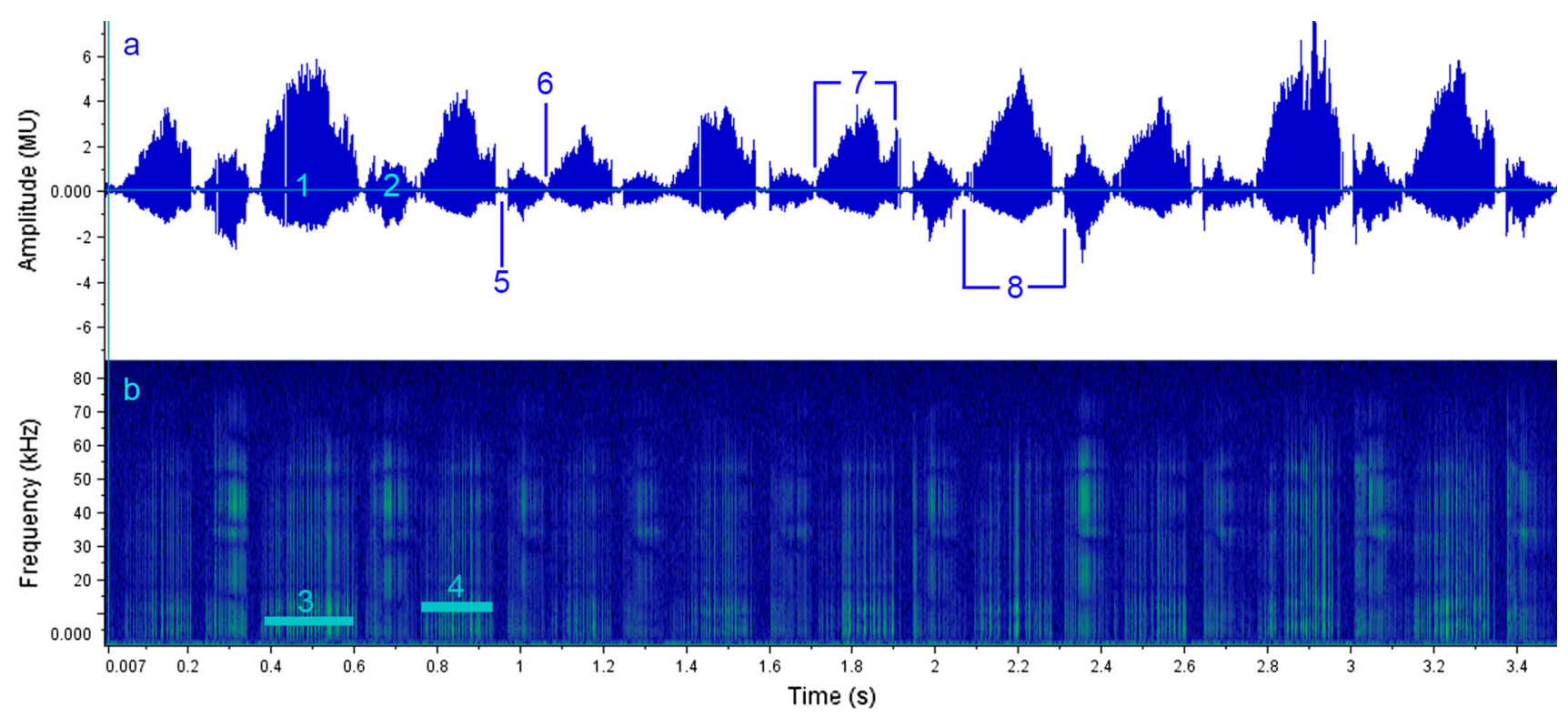

Fig. 2 The bi-phastic stridulation of N. americanus. An ocillogram (a) showing the temporal structure of stridulation showing the major pulse (1) that results when the beetle extends the abdomen beneath the plectra of the elytra, and the minor pulse (2) that results when the abdomen is retracted and returns to resting state. A spectrogram (b) showing the weak dominant frequency (3) of the stridulation, as well as the energy peak (4) of the pulse. Other temporal characters measured and compared in this study, and shown on the ocillogram (b), include the interpulse interval (5) of the major pulse and of the minor pulse (6). The major pulse duration (7) as indicated by the beginning and end of the pulse, and is similarly measured for the minor pulse, and the pulse period (8) used in calculating the duty cycle [(pulse duration/pulse period) $\times 100]$

Table 1 Comparison of mean \pm SD for twelve acoustic characters of $N$. americanus, prior to and following wing clipping

\begin{tabular}{|c|c|c|c|c|c|c|}
\hline & Acoustic character & $\begin{array}{l}\text { Prior to wing clipping } \\
\text { (value } \pm \text { SD) }\end{array}$ & $\begin{array}{l}\text { Following wing clipping } \\
\text { (value } \pm \text { SD) }\end{array}$ & Statistic & $d f$ & Significance \\
\hline \multirow[t]{6}{*}{ Major pulse } & Dominant frequency $(\mathrm{kHz})$ & $4.988 \pm 1.191$ & $5.224 \pm 1.809$ & -0.694 & 9 & 0.505 \\
\hline & Energy peak* $(\mathrm{kHz})$ & $8.790 \pm 4.144$ & $12.332 \pm 6.340$ & 2.179 & 9 & 0.057 \\
\hline & Syllables per pulse (\#) & $88.123 \pm 11.854$ & $86.411 \pm 11.161$ & 0.612 & 9 & 0.556 \\
\hline & Pulse duration (ms) & $0.158 \pm 0.025$ & $0.154 \pm 0.019$ & 0.670 & 9 & 0.520 \\
\hline & Inter-pulse interval (ms) & $0.041 \pm 0.017$ & $0.042 \pm 0.014$ & -0.278 & 9 & 0.787 \\
\hline & Duty cycle & $0.805 \pm 0.055$ & $0.791 \pm 0.057$ & 1.488 & 9 & 0.171 \\
\hline \multirow[t]{6}{*}{ Minor pulse } & Dominant frequency $(\mathrm{kHz})$ & $38.355 \pm 3.470$ & $35.443 \pm 6.698$ & 1.889 & 9 & 0.091 \\
\hline & Energy peak (kHz) & $34.343 \pm 7.862$ & $34.626 \pm 5.765$ & -0.094 & 9 & 0.928 \\
\hline & Syllables per pulse (\#) & $66.407 \pm 13.159$ & $61.416 \pm 14.123$ & 1.418 & 9 & 0.190 \\
\hline & Pulse duration (ms) & $0.079 \pm 0.009$ & $0.079 \pm 0.016$ & -0.111 & 9 & 0.914 \\
\hline & Inter-pulse interval* (ms) & $0.067 \pm 0.030$ & $0.118 \pm 0.072$ & -2.830 & 9 & 0.020 \\
\hline & Duty cycle & $0.572 \pm 0.122$ & $0.519 \pm 0.144$ & 1.709 & 9 & 0.122 \\
\hline
\end{tabular}

Characters that add significant difference to the variation are indicated by an asterisk $(*)$

\section{Breeding Experiments}

Due to low mass variation, carcass size was not related to the number of offspring produced $(\overline{\mathrm{x}}=137.1 \pm 8.15$; Pearson Correlation $=0.178, d f=48, P=0.159)$. Brood chamber preparation and copulation occurred in all pairings in all treatments. The distribution for the number of offspring by treatment failed the Shapiro-Wilk test for normality
(Shapiro-Wilk $=0.756, d f=51, P<0.001)$ and were resistant to transformation, thus we tested our data using nonparametric techniques. We found a significant difference in the number of offspring across predictor classes (KruskalWallis Rank Sum test, $\mathrm{H}=32.260, d f=3, P<0.001$ ), and post hoc tests confirmed a significant difference in offspring number between control breedings $(\bar{x}=17.71 \pm 8.13$, $\mathrm{N}=28$ ) and both the female-clipped treatments 


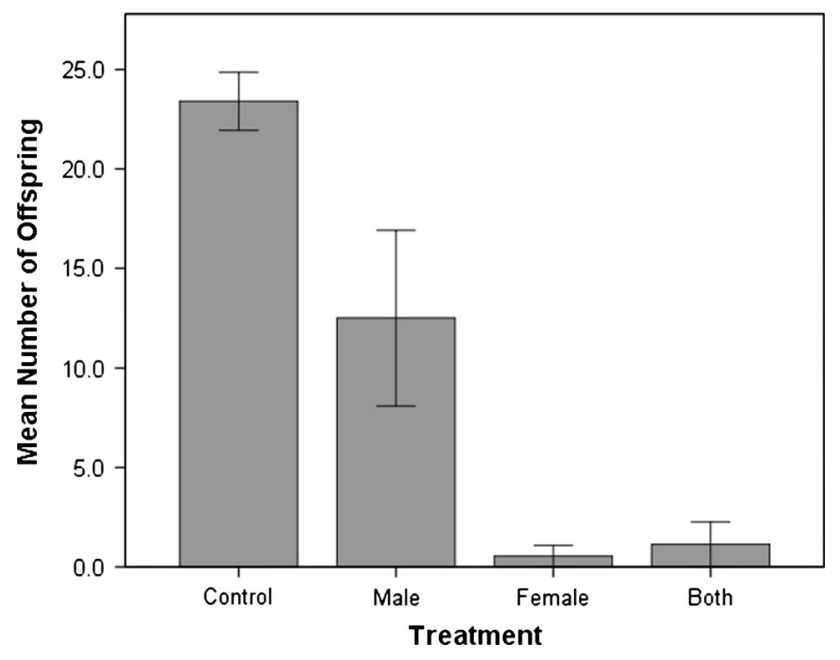

Fig. 3 The mean number \pm SD of $N$. americanus offspring by experimental treatment. There was a significant difference across groups in the number of offspring to elcose as adults (Kruskal-Wallis test, $\mathrm{H}=37.26, d f=3, P \leq 0.001$ ), and post hoc tests confirmed a significant difference in offspring number between control breedings $(\overline{\mathrm{x}}=17.71 \pm 8.13, \mathrm{~N}=28)$ and both the female-clipped treatments $(\overline{\mathrm{x}}=0.55 \pm 1.81, \mathrm{H}=4.69, P<0.001, \mathrm{~N}=11)$ and treatments in which both parents were clipped $(\overline{\mathrm{x}}=1.13 \pm 4.39, \mathrm{H}=-5.15$, $P<0.001, \mathrm{~N}=15)$. All other pairwise comparisons did not differ significantly in offspring number

$(\overline{\mathrm{x}}=0.55 \pm 1.81, \mathrm{~N}=11 ; \mathrm{H}=4.69, d f=1, P<0.001)$ and treatments in which both parents were clipped $(\overline{\mathrm{x}}=1.13 \pm 4.39, \mathrm{~N}=15 ; \mathrm{H}=-5.15, d f=1, \mathrm{P}<0.001$; Fig. 3). These two treatments did not differ from each other however $(\mathrm{H}=0.049$, $d f=1, \mathrm{P}=1.00)$. Treatments in which males were clipped did not differ from control $(\overline{\mathrm{x}}=12.50 \pm 13.95, \mathrm{H}=1.69, d f=1, \mathrm{P}=0.54)$, or from those with females clipped $(\mathrm{H}=-2.39, d f=1, P=0.10)$. There was a trend of male-clipped breedings exhibiting higher numbers of offspring than breedings in which both parents were clipped $(\mathrm{H}=-2.51, d f=1, \mathrm{P}=0.07)$, but adjusted $P$ values fell short of significance.

\section{Discussion}

Supporting our elytral modification hypothesis, elytron clipping was found to alter the acoustic characteristics of the stridulatory sound produced by $N$. americanus. Our findings, however, did not support our expectation that eytral modification would more profoundly alter spectral property. Rather, a temporal characteristic (interpulse interval of the minor pulse) showed the most significant change. The spectral change observed was consistent with the general model that a reduction in the size of a structure associated with sound production typically results in higher frequency tones. In this study, and in practice during field surveys, elytron clipping effectively reduces the overall size of the structure, and so one would expect that frequencies and peak energy of the sound should increase as the size of the acoustic structure is reduced. Also, structural modification could alter the stiffness of the elytra, which would also affect its natural frequency of vibration. Although the nature of the stridulation does not suggest that the elytron is acting as a resonator (see Hall et al. 2013), the changes in peak energy frequency in the minor pulse observed here indicate that the elytron may be contributing resonance-like characters. This result, therefore, leads to questions regarding the role of the elytra in sound production, if any. Sounds are a series of brief impulses that appear to correspond with discrete tooth impacts with no evidence of sustained oscillations. If the acoustic role of the elytra is broader than structural support for the plectra, research should focus on ascertaining the vibratory mechanics of elytral inclusion during stridulation.

Alteration of the temporal structure of stridulatory sound as a result of elytron clipping raises questions regarding the biomechanics of sound production in $N$. americanus. Abdominal movement during stridulation may explain this result, as observations of stridulation using high-speed videography at 100 frames-per-second revealed lateral movement of the abdomen in addition to dorso-ventral motion (Online Resource 1). If elytron clipping reduces the stiffness of the elytra or removes a portion the plectrum, it is possible that the beetle may not be able to maintain constant contact with the teeth of the stridens with both elytra for the entire length of the minor pulse, or that lateral abdominal rotation during stridulation causes the remaining plectra to miss contact with one or both of the pars stridens, lengthening the interpulse duration. Only subsequent motions in which the abdomen returns to nearresting position would restore contact between the remaining plectra and pars stridens. This lengthening of time between tooth strikes may also relate to a reduction in the general speed in which the abdomen is retracted during stridulation following elytron clipping may also be a condition-related phenomenon. Loss of haemolymph related to elytral modification may carry condition costs that are expressed in this element of the acoustic repertoire.

The experimental breeding treatments of elytron clipped adults support our prediction that the reproductive success of mated N. americanus would be reduced if sound characteristics of stridulation were altered as a result of elytron clipping. Since all reproductive behavior proceeded as expected using a well-established and approved breeding protocol, the significant reduction in brood size in elytralclipped breeding suggests an effect of the experimental treatment. The $90 \%$ reduction in brood success in treatments with an elytron clipped female compared to nonsignificant difference with elytron clipped males (Fig. 3) supports a model that sound production in females plays a 
more important role in brood success than does male stridulation. While our study does not directly address the function of stridulation during parental care behavior per $s e$, our results lead to questions regarding female-offspring communication and brood cohesion in $N$. americanus, as suggested by Pukowski (1933). The effect of elytron clipping in males may be more important in a natural setting in which brood defense from intruders by the male parent (not tested here) is often an integral dynamic in ultimate brood success (Scott 1990).

While elytral modification resulted in subtle temporal and spectral changes in the bioacoustics of $N$. americanus, the effects on fecundity were significant. Butler et al. (2012) found no significant influence of elytron clipping or elytral cauterization on mortality in a Nicrophorine surrogate species ( $N$. marginatus), but the authors did not measure changes in sound structure, fecundity, or other condition-sensitive behavioral metrics, or follow the fate of the treatment animals beyond the $36 \mathrm{~h}$ of post-operative observation in the lab. While there are few studies on the effect of marking procedures on invertebrates, in fish, modification of the fins has been shown to influence survivorship, growth, and behavior (Coble 1972; Crawford 1958; Nicola and Cordone 1973; Ricker 1949; Scheirer and Coble 1991). Similar effects have been found in toe-clipping in reptiles (Clarke 1972) and in mammals (Fairley 1982; Pavone and Boonstra 1985; Wood and Slade 1990). The combination of acoustic alteration along with the reduction in condition related to hemolymph loss (Sakaluk et al. 2004) after elytral modification likely explains the observed reduction in fecundity in $N$. americanus. The effect of elytral modification on animal behavior, especially behavior related to reproduction, should be thoroughly tested prior to implementation as recommended by Murray and Fuller (2000) to avoid harm to the individuals marked or to the larger metapopulation (Zann and Runciman 1994).

The marking technique of elytron clipping has been used in field surveys for the American burying beetle since its listing as a Category I Endangered Species in 1989, and is commonly employed during reintroductions of lab-raised stock to new field locations, either through the use of a $\mathrm{V}$-notch or cauterized punctures of the elytra to supplement external tags (Butler et al. 2012; Goldwasser et al. 1993). While elytron clipping was a marking technique prescribed by the US Fish and Wildlife Service as a fail-safe measure to ensure that no individual beetle was counted twice during a survey in the event that other non-permanent marking techniques (enamel paint, numbered bee tags) fail in the field, here we show for the first time that modification of an anatomical structure related to sound production during the course of field surveys carries a direct fitness cost to marked individuals (see Fig. 3), and recommend the replacement of this class of marking techniques with noninvasive methods.

Hagler and Jackson (2001) provide a thorough review of insect marking methods that researchers have used in mark-capture and mark-release-recapture studies. In most cases, field studies for $N$. americanus are mark-releaserecapture studies (typically for purposes of population estimation and/or population monitoring) in which identification to the individual level is required. In this context, researchers should consider using marking techniques that are durable and non-toxic, and allow obvious identification of marked individuals under field conditions. Of the techniques that have been used for this purpose, alphanumeric tags, sequentially numbered bee tags, and unique combinations of colored enamel paint dots are likely the least invasive techniques that could be used during $N$. americanus field studies. Another commonly used method for marking elytra of beetles has been described by Unruh and Chauvin (1993) and involves applying an individually specific pattern of pin pricks to the elytra. This semiinvasive method is applied using the tip of a fine insect pin, and we (RJS) have used a similar method of identification at the Rocky Mountain Biological Laboratory field site to individually identify Nicrophorus investigator, N. guttula, and $N$. defodiens, and although changes in sound characteristics and reproductive success has not been tested, we have not observed any changes in behavior after applying this technique (see Goldwasser et al. 1993). These techniques should be tested prior to deployment, however, to ensure that there is no effect on the animal's behavior (Hagler and Jackson 2001), including ultimate fitness.

Acknowledgments This work was funded by grants to C. Hall from the US Fish and Wildlife Service and the Nature Conservancy of Oklahoma. The authors thank Bob Merz and the St. Louis Zoo Center for American Burying Beetle Conservation, and Lou Perotti and the Roger Williams Park Zoo American Burying Beetle Repopulation Project, Augustana College, and Idaho State University.

Open Access This article is distributed under the terms of the Creative Commons Attribution License which permits any use, distribution, and reproduction in any medium, provided the original author(s) and the source are credited.

\section{References}

Alexander RD (1962) Evolutionary change in cricket acoustical communication. Evolution 16:443-467

Alexander RD (1967) Acoustical communication in arthropods. Annu Rev Entomol 12:495-526

Alexander RD, Moore TE, Woodruff RE (1963) The evolutionary differentiation of stridulatory signals in beetles (Insecta: Coleoptera). Anim Behav 11:111-115

Anderson RS (1982) The decreasing abundance of Nicrophorus americanus (Coleoptera: Silphidae) in eastern North America. Coleopt Bull 36:362-365 
Arrow GJ (1942) The origin of stridulation in beetles. Proc R Entomol Soc A 17:7-9

Bedick JC, Ratcliffe BC, Hoback WW, Higley LG (1999) Distribution, ecology, and population dynamics of the American burying beetle (Nicrophorus americanus Olivier (Coleoptera, Silphidae)) in south-central Nebraska, USA. J Insect Conserv 3:171-181

Bennet-Clark HC (1970) The mechanism and efficiency of sound production in mole crickets. J Exp Biol 52:619-652

Bennet-Clark HC (1975) Sound production in insects. Sci Prog 62:263-283

Bennet-Clark HC (1989) Songs and the physics of sound production. In: Huber F, Moore T, Loher W (eds) Cricket behavior and neurobiology. Cornell University Press, Ithaca

Bennet-Clark HC (1998) Size and scale effects as constraints in insect sound communication. Philos Trans R Soc B 353:407-419

Bennet-Clark HC (1999) Resonators in insect sound production: how insects produce loud pure-tone songs. J Exp Biol 202:3347-3357

Bradbury JW, Vehrencamp SL (1998) Principles of animal communication. Sinauer Associates Inc, Sunderland

Buchler ER, Wright TB, Brown ED (1981) On the functions of stridulation by the passalid beetle Odontotaenius disjunctus (Coleoptera, Passalidae). Anim Behav 29:483-486

Burley N (1985) Leg-band color and mortality patterns in captive breeding populations of zebra finches. The Auk 3:647-651

Butler SR, Jurzenski J, Hoback WW (2012) Evaluation of marking techniques, mark retention, and mortality due to marking of burying beetles (Coleoptera: Silphidae). Coleopt Bull 66:149-154

Claridge MF (1974) Stridulation and defensive behavior in ground beetle, Cychrus caraboides (L.). J Entomol Ser A 49:7-15

Clarke RD (1972) The effect of toe clipping on survival in Fowler's toad (Bufo woodhousei fowleri). Copeia 1972:182-185

Coble DW (1972) Vulnerability of fin clipped bluegill to largemouth bass predation in tanks. Trans Am Fish Soc 101:563-565

Crawford RW (1958) Behaviour, growth and mortality in the bluegill, Lepomis macrochirus Rafinesque, following fin clipping. Copeia 1958:330-331

Creighton JC, Vaughn CC, Chapman BR (1993) Habitat preference of the endangered American burying beetle (Nicrophorus americanus) in Oklahoma. Southwest Nat 38:275-306

Creighton J, Bastarache R, Lomolino M, Belk M (2009) Effect of forest removal on the abundance of the endangered American burying beetle, Nicrophorus americanus (Coleoptera: Silphidae). J Insect Conserv 13:37-43

Deroe C, Pasteels JM (1977) Defensive mechanisms against predation in the Colorado beetle (Lepinotarsa decemlineata Say). Arch Biol 88:289-304

Fairley JS (1982) Short-term effects of ringing and toe-clipping on the recapture of wood mice (Apodemus sylvaticus). J Zoo 197:295-297

Forrest TG, Green DM (1991) Sexual selection and female choice in mole crickets Scapteriscus Gryllotalpidae: modelling the effects of intensity and male spacing. Bioacoustics 3:93-110

Goldwasser L, Schatz GE, Young HJ (1993) A new method for marking Scarabaeidae and other Coleoptera. Coleopt Bull $1: 21-26$

Hagler JR, Jackson CG (2001) Methods for marking insects: current techniques and future prospects. Annu Rev Entomol 46:511-543

Hall CL, Mason AC, Howard DR, Padhi A, Smith RJ (2013) Description of acoustic characters and stridulatory pars stridens of Nicrophorus (Coleoptera: Silphidae): a comparison of eight North American species. Ann Entomol Soc Am 106:661-669

Howard DR, Hill PSM (2006) Morphology and calling song characteristics in Gryllotalpa major Saussure (Orthoptera: Gryllotalpidae). J Orthoptera Res 15:53-57
Huerta C, Halffter G, Fresneau D (1992) Inhibition of stridulation in Nicrophorus (Coleoptera: Silphidae): consequences for reproduction. Elytron 6:151-157

Hyder DE, Oseto CY (1989) Structure of the stridulatory apparatus and analysis of the sound produced by Smicronyx fulvus and Smicronyx sordidus (Coleoptera, Curculionidae, Erirrhininae, Smicronychini). J Morphol 201:69-84

Kasper J, Hirschberger P (2005) Stridulation in Aphodius dung beetles: songs and morphology of stridulatory organs in North American Aphodius species (Scarabaeidae). J Nat Hist 39:91-99

Kozol AJ, Scott MP, Traniello JFA (1998) The American burying beetle, Nicrophorus americanus: studies on the natural history of a declining species. Psyche 95:167-176

Mankin RW, Moore A, Samson PR, Chandler KJ (2009) Acoustic characteristics of dynastid beetle stridulations. Fla Entomol 92:123-133

Milne LJ, Milne MJ (1944) Notes on the behavior of burying beetles (Nicrophorus spp.). J N Y Entomol Soc 52:311-327

Montealegre-Z F, Mason AC (2005) The mechanics of sound production in Panacanthus pallicornis (Orthoptera: Tettigoniidae: Conocephalinae): the stridulatory motor patterns. J Exp Biol 208:1219-1237

Morris GK, Beier M (1982) Song structure and description of some Costa Rican katydids (Orthoptera: Tettigoniidae). Trans Am Entomol Soc 108:287-314

Murray DL, Fuller MR (2000) A critical review of the effects of marking on the biology of vertebrates. Research techniques in animal ecology: controversies and consequences. Columbia University Press, New York, pp 15-64

Nicola SJ, Cordone AJ (1973) Effects of fin removal on survival and growth of rainbow trout (Salmo gairdneri) in a natural environment. Trans Am Fish Soc 102:753-758

Pavone LV, Boonstra R (1985) The effects of toe clipping on the survival of the meadow vole (Microtus pennsylvanicus). Can J Zool 63:499-501

Prestwich KN (1994) The energetics of acoustic signaling in anurans and insects. Am Zool 34:625-643

Pukowski E (1933) Ecological investigation of Necrophorus F. Z Morphol Oekol 27:518-586

Ricker WE (1949) Effects of removal of fins upon the growth and survival of spiny-rayed fishes. J Wildl Manage 13:29-40

Ryan MJ (1988) Energy, calling, and selection. Am Zool 28:885-898

Sakaluk SK, Campbell MT, Clark AP, Johnson JC, Keorpes PA (2004) Hemolymph loss during nuptial feeding constrains male mating success in sagebrush crickets. Behav Ecol 15:845-849

Scheirer JW, Coble DW (1991) Effects of Floy FD-67 Anchor tags on growth and condition of northern pike. N Am J Fish Manage 11:369-373

Schumacher R (1973) Contribution to knowledge of stridulatory apparatus of native Necrophorus Species (Necrophorus Humator Ol, Necrophorus Investigator Zetterst, Necrophorus Vespilloides Herbst) (Insecta, Coleoptera). Z Morphol Tiere 75:65-75

Scott MP (1990) Brood guarding and the evolution of male parental care in burying beetles. Behav Ecol Sociobiol 26:31-39

Sikes DS, Raithel CJ (2002) A review of hypotheses of decline of the endangered American burying beetle (Silphidae: Nicrophorus americanus Olivier). J Insect Conserv 6:103-113

Unruh TR, Chauvin RL (1993) Elytral punctures: a rapid, reliable method for marking Colorado potato beetle. Canadian Ento 125:55-63

Wood MD, Slade NA (1990) Comparison of ear-tagging and toe clipping in prairie voles, Microtus ochrogaster. J Mammal 71:252-255

Zann R, Runciman D (1994) Survivorship, dispersal and sex ratios of zebra finches Taeniopygia guttata in southeast Australia. Ibis 136:136-143 